\title{
Articles
}

\section{Is Willingness to Communicate Associated With More Positive Online Chat Experiences?}

\author{
Charles M. Mueller \\ Fuji Women's University
}

Allen Walzem

Southern Taiwan University of Science and Technology

Willingness to Communicate (WTC) has been put forth as a model (MacIntyre et al., 1998) of situations and attitudes that facilitate L2 learners' openness to opportunities for L2 use and concomitant behaviors. In the current study, this model's criterion-related validity was examined through a comparison of WTC survey results with results of a subsequently administered survey regarding the online chat experiences of Japanese and Taiwanese learners of English. The participants $(N=190)$ were Japanese and Taiwanese EFL students who took part in an online chat program, in class and/or as homework. Results showed a consistent association between WTC components and participants' perception that the chats had been useful in promoting English proficiency as well as knowledge and interest in their chat partner's culture. The study suggests that WTC may serve as a valuable construct for predicting learners' perceptions of telecollaboration as a language-learning platform.

Willingness to Communicate (以下, WTCと略す)は、第二言語学習者の第二言語の使用やそ れに付随した行動の機会に対する開放性を促す状況および態度のモデルとして提唱されてきた (MacIntyre et al., 1998)。本研究では、日本人・台湾人英語学習者のWTCの調査結果とオンラ イン・チャット体験に関する事後調査結果の比較を通して、当該モデルの基準関連妥当性を調 查した。被験者 $(N=190)$ は外国語として英語を学ぶ日本人・台湾人学生のうち、授業中または

https://doi.org/10.37546/JALTJJ42.2-1

JALT Journal, Vol. 42, No. 2, November 2020 
宿題としてオンライン・チャット・プログラムに参加した者である。その結果、英語の習熟ならび にチャット相手の文化に関する知識・興味の深化にチャットが有効だったという参加者の認識と WTCの構成要素との間に一貫した関連を認めた。本研究は, 言語学習のプラットフォームとして のテレコラボレーションに対する学習者の認識を推測するのにWTCが価值ある構成概念として 利用できる可能性を示唆した。

Keywords: CALL; motivation; online chat; telecollaboration; WTC

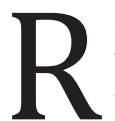

esearch has demonstrated that interaction is a powerful means of boosting L2 proficiency (Mackey \& Goo, 2007). While interacting, learners often receive corrective feedback, which has been shown to have a positive and lasting effect on L2 learning (Li, 2010) due to its promotion of greater noticing of target forms in the input (Mackey, 2006). Unfortunately, interaction is often hindered in EFL settings by learners' hesitancy to use the target language with peers with whom they share an $\mathrm{L} 1$, and a tendency to revert to the L1 as soon as communication problems occur (Freiermuth \& Jarrell, 2006). In addition, when learners share an L1, they often adopt a speech style in which various discourse functions tend to be performed in the L1 (Hancock, 1997).

In EFL settings, one novel solution for addressing this issue is to use social networking technologies to connect learners with either NSs or NNSs learning the same target language (for a meta-analysis on effectiveness, see Ziegler, 2016). Empirical research has shown that interacting with L1-different interlocutors results in more negotiation for meaning and L2 production (Bueno-Alastuey, 2011, 2013). Synchronous online video chat is particularly attractive as it allows learners to interact in real time using a platform in which visual information is also available.

Yet for some EFL learners with minimal experience interacting one-onone with a speaker of a different L1, online chat can pose a challenge. L2 learners' ability to successfully negotiate this challenge is likely to be associated with individual differences, such as the cognitive, affective, and situational factors put forth in the willingness to communicate (WTC) framework (MacIntyre et al., 1998).

The aim of the current study was, thus, to compare learners' responses to a battery of survey questions related to WTC given before their online chat experiences with their responses to a second survey administered at the end of the semester after they had engaged in online chats. From a theoretical standpoint, the findings are valuable as an examination of the criterion-based validity of the WTC construct. From a practical standpoint, 
they provide insights into both attitudinal and situational factors that promote positive synchronous face-to-face chat experiences. This paper begins with an overview of research on the use of online chat for language learning and WTC; the Results section presents an analysis of the survey data, focusing on correlations between the two sets of survey instruments; and the Discussion section offers an examination of the theoretical and practical implications of the findings.

\section{Telecollaboration}

Telecollaboration is defined by Belz (2003) as "institutionalized, electronically mediated intercultural communication under the guidance of a linguacultural expert (i.e., teacher) for the purposes of foreign language learning and the development of intercultural competence" (p. 2). Belz's definition suggests that telecollaboration enables the synergistic pursuit of both linguistic and intercultural competence (Byram, 1997). There has been a marked increase in articles on telecollaboration in recent years due to the ever-increasing accessibility of communication technology and greater awareness of the importance of learning language through purposeful communicative events that involve an authentic need to communicate (Dooly, 2017; Freiermuth \& Huang, 2012), and findings that show that telecollaboration promotes more equal participation than face-to-face interactions (Warschauer, 1996).

As implemented in second language programs, telecollaboration takes various forms. On a technical level, it can involve synchronous (e.g., instant messaging) or asynchronous (e.g., emailing) interaction, or a combination of both. Synchronous interaction often involves the use of a webcam (Develotte et al., 2010), allowing for visual support and the close simulation of an actual face-to-face encounter. In terms of pairings, learners can interact one-on-one or in groups, and the pairings can remain stable over multiple chat sessions or can be switched periodically.

A key decision when designing telecollaboration programs concerns the combination of L1s and target languages. In bilingual exchanges, students can learn each other's L1s (Cziko, 2004; Tian \& Wang, 2010). This provides students with the opportunity to engage with NSs of the target language, but if done as an exchange, it also entails learners spending equal time using their own L1 with their partner. On the other hand, lingua franca exchanges (Freiermuth \& Huang, 2018), in which both interlocutors are NNSs speaking the same target language, have the benefit of effectively doubling the proportion of time devoted to interaction in each learner's target language. 
In telecollaboration, lesson structures and tasks vary (Kurek \& MüllerHartmann, 2017; O'Dowd \& Ware, 2009). They are often organized as activities performed outside of class time but can be done in class in some situations if the schedules, often complicated by time differences, are aligned. In many cases, particularly when the interaction is synchronous and occurs in class, the activities involve information exchange. In other cases, especially with higher proficiency learners, learners can do projects involving cultural comparison or analysis. Finally, telecollaboration can be initiated by instructors or by the learners themselves.

\section{Willingness to Communicate (WTC)}

In the current research, learner perceptions of telecollaboration were examined in association with willingness to communicate. In the WTC model (MacIntyre, 2007; MacIntyre et al., 1998), WTC and associated factors are depicted as a pyramid consisting of six layers (numbered from top to bottom): (1) communication behavior, (2) behavioral intention, (3) situated antecedents, (4) motivational propensities, (5) affective-cognitive context, and (6) social and individual context. These six layers, in turn, are associated with the 12 constructs shown in Figure 1. The model depicts factors ranging from highly transient situational variables (Cao \& Philp, 2006; MacIntyre \& Legatto, 2011) to relatively stable variables such as personality traits (MacIntyre \& Charos, 1996).

Two key variables thought to underlie WTC in both the L1 and L2 are communication apprehension (MacIntyre, 1994; MacIntyre et al., 1997) and perceived competence (Yashima, 2002). Some research (e.g., MacIntyre et al., 2003) suggests that learners using the L2 in more naturalistic situations outside of the classroom are especially liable to experience anxiety, which is unfortunate because anxious learners communicate less information in the L2 and are less expressive in general (MacIntyre et al., 1997). Gardner et al. (1989) suggest that perceived competence partly reflects actual competence and leads to reduced levels of anxiety.

Some research supports the notion that WTC predicts the initiation of communication in the L2. For example, MacIntyre et al. (1999), using a structural equation model, found that measures of trait WTC were correlated with participants' willingness to volunteer for a portion of a communication study and, similarly, that stated perceived competence predicted the time spent on a speaking task.

Learners' WTC also appears to be associated with reasons for studying the L2. A study of Grade 9 students in an L2 French immersion program 
(MacIntyre et al., 2001) showed that five typical reasons for study (travel, job, friendship, personal knowledge, and academic achievement) were all associated with WTC both inside and outside of class. Moreover, social support, particularly the support of friends, was found to be associated with studying the L2 for travel and friendship.

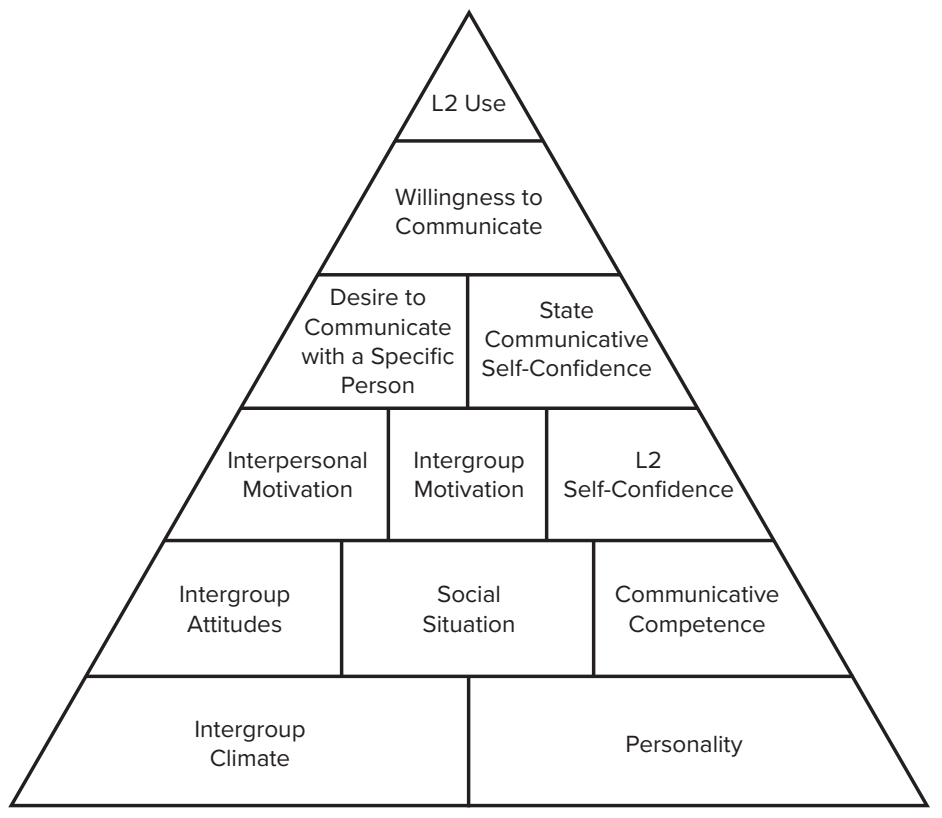

Figure 1. The heuristic model of variables influencing WTC (adapted from MacIntyre et al., 1998, p. 547).

\section{Telecollaboration and WTC}

Recently, a number of studies have examined the relationship between telecollaboration and motivational factors such as those discussed in the WTC model. Generally speaking, participants in telecollaboration programs have reported positive experiences that enhance their L2 motivation. For example, Helm (2015) conducted a survey of over 100 university educators and over 100 students in the EU who had participated in telecollaboration. The overwhelming majority of instructors and students reported that the experience was positive. Research on specific telecollaboration projects (Meunier, 1998) generally reports similar results. Typical in this regard is Meguro and Bryant's (2010) case study of bilingual language exchanges via Skype 
between a U.S. and Japanese university. Among their participants (who were U.S. university students), $93.6 \%$ said that they enjoyed the activity, $87.1 \%$ that the activity increased their confidence, $90.3 \%$ that it improved their cultural knowledge of Japan, $96.8 \%$ that it improved their speaking skills, and $100 \%$ that it enhanced their listening skills. These subjective impressions of improvement are supported by some research showing improved linguistic competence based on objective measures. For example, Saito and Akiyama (2017) found that online chat, in comparison with more traditional classroom activities, led to improvements in comprehensibility, fluency, and lexicogrammar.

Some research in this area (e.g., Freiermuth \& Jarrell, 2006) has specifically employed the WTC framework. For example, Freiermuth and Huang (2012) conducted a qualitative study of two groups of English learners who engaged in synchronous chat (texting). The study is particularly relevant to the present research as it involved participants (20 students from Japan and 19 from Taiwan) with the same L1 backgrounds as those in the current study. The study examined the results in terms of WTC, task attractiveness, task innovativeness, and need to communicate in the target language. Regarding WTC, analysis of transcripts suggested that the participants felt relatively high levels of confidence and low levels of anxiety, perhaps due to the use of texting instead of speaking.

In the current study, two lacunae in the research are addressed. First, in previous studies, the predictive validity of the WTC framework for telecollaboration outcomes has not been examined. Second, few studies have focused on individual differences that may predict learners' perceptions of telecollaborative activities. Specifically, this study was designed to answer the following research questions:

RQ 1. Is EFL students' willingness to communicate (as assessed beforehand) correlated with their perceptions of the usefulness of telecollaboration (as assessed afterward) for language learning?

RQ 2. Are EFL students' learning orientations (as assessed beforehand) correlated with their perceptions of the utility of telecollaboration (as assessed afterward) for language learning?

RQ 3. Is EFL students' willingness to communicate (as assessed beforehand) correlated with their perceptions of the usefulness of telecollaboration (as assessed afterward) for promoting knowledge and interest in the chat partners' culture? 
RQ 4. Are EFL students' learning orientations (as assessed beforehand) correlated with their perceptions of the utility of telecollaboration (as assessed afterward) for promoting knowledge and interest in the chat partners' culture?

\section{Method}

To answer these four research questions, a survey-based study was conducted over the course of a semester.

\section{Participants}

The participants $(N=190)$ were 90 EFL students of English at a private women's university in Japan (taught by five different instructors) and $100 \mathrm{EFL}$ students from a private university in Taiwan (taught by a single instructor). The Japanese learners (all L1-Japanese) were 1st-year students enrolled in required oral English classes, with 80 majoring in English language and literature and the remaining 10 majoring in Japanese language and literature. Based on their TOEFL PBT scores, most were at the B1 level in terms of the Common European Framework of Reference (CEFR). The Taiwanese group, with the exception of one Vietnamese and two Korean students, consisted of L1-Chinese Taiwanese students majoring in English. Among the Taiwanbased participants, the in-class chat participants were 1st-year students in an English-only class focused on emotional intelligence and gender issues, whereas the chat-as-homework participants were 3rd- and 4th-year students in an oral English (i.e., conversation) class. The English proficiency of the 1st-year students was similar to that of their Japanese counterparts, but the proficiency of the 3rd- and 4th-year students was slightly higher (i.e., at or just below the B2 level).

About half of the participants ( 48 of those from the Japanese group and 50 from the Taiwanese group) did the online chat in class. The remaining participants did the online chat as homework. Among the Japanese participants, 36 of the participants who did the chat in class volunteered to do additional chats as homework for extra credit in another class. Additional qualitative data for the study came from informal conversations and interviews with the participants' more senior classmates (approximately 250 students) who also participated in online chats during the 3 years prior to the 190 participants who are the primary focus of the current study. 


\section{Setting}

Both the Taiwanese and Japanese participants primarily used Skype to engage in synchronous face-to-face chats. Research on the use of Skype in telecollaboration (Akiyama, 2014) has indicated that the platform has a number of features that facilitate successful communication. For the in-class chats on the Japanese side, participants from two classes met in a computer room and used newly installed individual computers equipped with headphones and webcams. The Taiwanese met in a similarly equipped computer room. Two instructors were in the Japanese class, but only one was present in the Taiwanese class. During the chat, the instructors from both countries were periodically in contact via Skype to coordinate regarding various logistical problems such as student absences or computer malfunctions and to ensure that each student was able to connect with a partner.

\section{Instruments and Materials}

The participants who did the chat in class participated in six sessions that focused on (1) personal introductions, (2) past school experiences, (3) dating, (4) comparisons of costs in their respective countries, (5) rapid information exchange, and (6) travel. For the rapid information exchange, participants had to obtain basic information from a partner in two to three minutes before switching to a new partner. The chat-as-homework participants were given four assignments focused on (1) personal introductions; (2) school experiences; (3) friends, dating, and marriage; and (4) TV, movies, and music. Worksheets were created for each chat topic. The worksheets gave a brief introduction to the topic, encouraged participants to ask follow-up questions, suggested pertinent questions, and provided useful words and expressions. Most were one page in length, but a few were longer.

Two sets of survey instruments were used in the study. The first set was adapted, with only very minor changes (e.g., with brief explanations for unfamiliar terms such as the game Monopoly), from a survey battery created by MacIntyre et al. (2001) used to measure (1) WTC in the classroom, (2) WTC outside the classroom, and (3) orientations for language learning. Cronbach's alpha, a measure of reliability, has been reported after each component of the survey based on participant responses in the current study.

WTC in the classroom was further subdivided into WTC items related to speaking $(\alpha=.87)$, reading $(\alpha=.94)$, writing $(\alpha=.95)$, and listening $(\alpha=$ .92). WTC outside the classroom was similarly divided into speaking $(\alpha=$ .91), reading ( $\alpha=.92)$, writing $(\alpha=.93)$, and listening $(\alpha=.91)$. Orientations 
were divided into items related to travel, knowledge, friendship, jobs, and school achievement. As can be seen from the reliability estimates, the items had good reliability. The two WTC measures each consisted of 27 items designed to measure students' willingness to engage in L2 communication in academic and nonacademic settings. The orientations survey, based on that of an earlier study (Clément \& Kruidenier, 1983), examined participants' reasons for learning the L2 in terms of five categories: (1) travel $(\alpha=.75)$, (2) knowledge $(\alpha=.68)$, (3) friendship ( $\alpha=.83)$, (4) jobs $(\alpha=.81)$, and (5) school achievement $(\alpha=.67)$.

The Chat Experience Survey, created for the current study, employed a six-point Likert response scale to measure participants' subjective evaluation of the online chat experience. The survey consisted of 12 items. The seven main items of interest, shown in Table 1, fell into two content areas: Three items $(\alpha=.68)$ sought to determine whether participants felt that the chats improved their cultural knowledge and interest in the target culture, and four items $(\alpha=.77)$ were related to perceived gains in L2 knowledge. An additional five items asked for practical information, such as the number of chats completed. To ensure that participants understood the survey items and could respond in a timely manner, all items in both sets of survey instruments were translated by native speakers into Chinese and Japanese.

Table 1. Items in the Chat Experience Survey

\section{Cultural-learning items}

1. I learned a lot about Japanese/Taiwanese culture during the chat.

2. After the chat, I'm more likely to visit Japan/Taiwan.

3. Because of the chat experience, I'm more interested in watching movies or reading books about Japan/Taiwan.

\section{Language-learning items}

1. I felt that the chat improved my English speaking ability.

2. I think the chat helped me learn many new words and expressions.

3. I would recommend online chats to students who want to improve their English.

4. Having done the chat, I now feel less anxious about making mistakes when speaking English. 


\section{Procedures}

Participants were first required to create Skype accounts. They all received a 30-minute training session on the use of Skype along with a handout explaining how to sign up and use the service. Those doing the chats in class were then asked to contact the overseas partner assigned to them for that session. The chats were done during 45-minute classes throughout the term, which meant that the actual chat time was usually slightly shorter (about 40 minutes) because it took participants some time to log into Skype and contact their partner. When the number of students in the Japanese and Taiwanese classes did not match, some of the participants were paired two to one. Participants doing the chats outside of class were given their partner's email and asked to contact their partner to set up a time to chat. If they did not have access to Skype at home, they were encouraged to use other platforms, such as Line, after confirming that their partner had access to that platform and agreed to do so.

Participants took the WTC survey battery at the beginning of the semester prior to all the chats and then took the Chat Experience Survey at the end of the semester, after the final chat. All surveys were taken online using the Quia survey system. Chat worksheets were provided to participants and reviewed in class prior to the chats, and then they were handed in as homework after the chats.

\section{Results}

The objectives of this study were to assess the correlations among survey responses related to WTC both in and outside the classroom, languagelearning orientations, and participants' chat experiences. The descriptive results for the surveys are reported below, followed by an analysis of the correlations.

\section{WTC Survey}

Survey responses from the Taiwanese and Japanese participants were virtually identical. For this reason, and because the study's research questions were not focused on cross-cultural differences, all the data were pooled in the analysis. Table 2 shows the WTC survey responses $(N=190)$ to items on a six-point Likert scale. Most responses were around 3.5, the median response on the scale. Participants reported slightly more WTC for the category WTC in the classroom, possibly due to the affective support afforded by typical classroom environments. Paired-sample $t$-tests comparing responses for 
WTC in the classroom versus WTC outside the classroom for each of the four skills showed statistically higher outside-the-classroom responses for writing, $t(189)=2.24, p<.001$, and listening, $t(189)=3.01, p=.003$, but not for speaking, $t(189)=1.07, p=.284$ or for reading, $t(189)=2.24, p=.026$, at an alpha of .012 (a more stringent alpha to correct for use of multiple $t$-tests).

Table 2. WTC Survey Results

\begin{tabular}{lcccccccc}
\hline \multirow{2}{*}{ WTC } & \multicolumn{2}{c}{ Speaking } & \multicolumn{2}{c}{ Reading } & \multicolumn{2}{c}{ Writing } & \multicolumn{2}{c}{ Listening } \\
\cline { 2 - 9 } & $M$ & $S D$ & $M$ & $S D$ & $M$ & $S D$ & $M$ & $S D$ \\
\hline In the classroom & 3.44 & 0.78 & 3.57 & 0.88 & 3.47 & 0.90 & 3.63 & 0.88 \\
\hline $\begin{array}{l}\text { Outside the } \\
\text { classroom }\end{array}$ & 3.39 & 0.86 & 3.49 & 0.88 & 3.34 & 0.88 & 3.52 & 0.84 \\
\hline
\end{tabular}

Preliminary analyses of the significance (at an alpha of .01) showed that intercorrelations between the eight WTC categories were significant, ranging from $r=.62$ to .88 , as were the intercorrelations between the orientations, which ranged from $r=.41$ to .73 . These are similar to those obtained in previous research (e.g., MacIntyre et al., 2001).

\section{Language-Learning Orientations}

Participants' $(N=190)$ orientations toward language learning, based on mean responses to the four items related to each of the five orientation categories, are shown in Table 3. Responses were made using a six-point Likert scale $(1=$ strongly disagree to $6=$ strongly agree). As can be seen, participants indicated that all five categories represented important motivations for their English study, with future employment being of particular concern.

Table 3. Language-Learning Orientations

\begin{tabular}{lcc}
\hline Orientation & $M$ & $S D$ \\
\hline Job & 5.29 & 0.67 \\
Travel & 5.19 & 0.70 \\
Friendship & 5.09 & 0.75 \\
Knowledge & 5.09 & 0.68 \\
School & 5.06 & 0.79 \\
\hline
\end{tabular}




\section{Chat Experience Survey}

Fewer participants $(n=136)$ filled out the final Chat Experience Survey than filled out the preliminary survey. Among those who did (69 from the Taiwanese group and 67 from the Japanese group), the mean response was $4.42(S D=0.70)$ for the Culture Learning items and $4.28(S D=0.63)$ for the Language Learning items. As the median response of the scale was 3.5, the responses suggest that participants felt that the chats fostered their knowledge and interest in the target culture as well as their L2 learning. The correlation between the two sets of items was $r=.46(p<.001)$. Five additional survey questions focused on objective information. Participants reported completing an average of 4.1 chat sessions (with a range of 1 to 6 ).

\section{Correlations Among WTC, Orientations, and Chat Experiences}

Table 4 shows the relationship between WTC and orientations $(N=190)$. In the analysis, the polarity of the orientation-related items was arranged so that a high positive correlation corresponds to a positive relationship between a WTC category and an orientation.

Table 4. Correlations Among WTC Inside and Outside the Classroom and Orientations

\begin{tabular}{|c|c|c|c|c|c|}
\hline \multirow[t]{2}{*}{ WTC } & \multicolumn{5}{|c|}{ Orientations } \\
\hline & Job & Travel & Friendship & Knowledge & School \\
\hline \multicolumn{6}{|c|}{ In the classroom } \\
\hline Speaking & $.36^{*}$ & $.32 *$ & $.38^{*}$ & $.41^{*}$ & $.31^{*}$ \\
\hline Reading & $.47^{*}$ & $.34^{*}$ & $.34^{*}$ & $.41^{*}$ & $.21^{*}$ \\
\hline Writing & $.35^{*}$ & $.22^{*}$ & $.25^{*}$ & $.30^{*}$ & .18 \\
\hline Listening & $.44^{*}$ & $.32 *$ & $.34^{*}$ & $.38^{*}$ & $.20^{*}$ \\
\hline \multicolumn{6}{|c|}{ Outside the classroom } \\
\hline Speaking & $.33^{*}$ & $.27^{*}$ & $.33^{*}$ & $.42^{*}$ & $.34^{*}$ \\
\hline Reading & $.44^{*}$ & $.32^{*}$ & $.36^{*}$ & $.39 *$ & $.20^{*}$ \\
\hline Writing & $.39 *$ & $.27^{*}$ & $.30^{*}$ & $.34^{*}$ & $.22^{*}$ \\
\hline Listening & $.41 *$ & $.32 *$ & $.29^{*}$ & $.31^{*}$ & .10 \\
\hline
\end{tabular}


As can be seen, all the correlations were positive. Using an alpha of .01, there was a significant correlation between orientations and WTC, except for those between two of the WTC categories and the school-based orientation (cf. MacIntyre et al., 2001). In the results, school-based orientations generally showed a much lower correlation with WTC, even when the WTC measures target WTC in the classroom. There was a consistently strong relationship between WTC and a knowledge-based orientation. It is also notable that the job-related orientation was strongly correlated with WTC for reading and listening (especially in the classroom). This may reflect a washback effect, namely, participants' awareness that entry into many English-related job fields requires high scores on exams that assess English reading and listening proficiency.

Of key interest in this research was the relationship between WTC, as assessed prior to the chat, and participants' perceived outcomes in terms of acquiring cultural knowledge and English language skills from the chat experience. Table 5 shows the correlation between participants' $(N=136)$ mean responses to WTC survey categories with mean responses to culturerelated knowledge and language learning on the Chat Experience Survey.

\section{Table 5. Correlation Between WTC and Perceived Utility of Chat}

\begin{tabular}{|c|c|c|}
\hline \multirow[t]{2}{*}{ WTC } & \multicolumn{2}{|c|}{ Perceived utility } \\
\hline & Culture & Language \\
\hline \multicolumn{3}{|c|}{ In the classroom } \\
\hline Speaking & $.29 * *$ & $.31^{* *}$ \\
\hline Reading & $.22^{*}$ & $.26^{* *}$ \\
\hline Writing & $.31^{*}$ & $.35^{* *}$ \\
\hline Listening & $.21^{*}$ & $.24^{* *}$ \\
\hline \multicolumn{3}{|c|}{ Outside the classroom } \\
\hline Speaking & $.22^{*}$ & $.27^{* *}$ \\
\hline Reading & $.22^{*}$ & $.26^{* *}$ \\
\hline Writing & $.29^{*}$ & $.34^{* *}$ \\
\hline Listening & $.25^{* *}$ & $.28^{* *}$ \\
\hline
\end{tabular}


As can be seen, all the correlations were positive and significant at the .05 level, with correlations that suggested low to moderate associations. In other words, the answers to RQ1 and RQ3 were positive, with marginally higher correlations between all WTC components and perceived languagerelated outcomes. Rather surprisingly, writing WTC showed the strongest association with perceived outcomes. It is not clear why there should be a stronger association between writing WTC and perceived outcomes than between speaking WTC and perceived outcomes. One possibility is that the association reflects the perceived importance of typing within the chat sessions; participants often dealt with communication breakdowns by using the text chat feature of Skype. Those with greater willingness to communicate in text-based chat may have had more successful communication and may have thus perceived the chats to be more beneficial in terms of language and cultural learning.

None of the correlations between language-learning orientations (assessed on the prechat WTC survey) and the two components of the Chat Experience Survey were significant at an alpha level of .05, so they have been omitted in Table 5. In other words, the answers to RQ2 and RQ4 were negative.

\section{Discussion}

The current study aimed to test the ability of WTC components to predict the extent to which learners perceive online chats as beneficial in terms of cultivating cultural knowledge and interests, as well as improving English skills. The findings indicate that WTC components, especially writing WTC, assessed prior to online chat assignments, are consistently associated with better perceived outcomes. On the other hand, language-learning orientations, while closely associated with WTC components, are not closely associated with perceived outcomes. The findings suggest that the skill-based WTC components may help teachers and institutions determine whether learners will find online chat programs worthwhile. At the same time, they suggest that measures to increase learners' WTC may help ensure that learners find the online chat experience rewarding.

The study has a number of limitations. The limited number of participants made it unfeasible to conduct more fine-grained comparisons of subgroups (e.g., further breakdown of results by participants' L1 or based on whether participants did the chats in class, as homework, or both). Furthermore, the participants who dutifully filled out the Chat Experience Survey were likely to differ from those who neglected to do so. This factor must be taken into 
account when considering analyses comparing the WTC and Chat Experience Survey responses.

Finally, both discussions with students and the course evaluation forms indicated that the online chat sessions were immensely popular. An extra item at the end of the participants' Chat Experience Survey asked if they ever initiated extracurricular chats with their language partner, whether to further their friendship or simply to practice English. Well over half $(62 \%)$ said they had done so, with $20 \%$ completing three extra chats and another $20 \%$ more than three extra chats. Furthermore, prior discussions with students who have been in the same Japan-Taiwan chat program during the previous 3 years have revealed that many students who engage in telecollaboration during their 1st year continue, on their own initiative, to make contact with their overseas partner throughout their following 3 years at university, and in some cases, visit their partner during a school break. These anecdotes further suggest the tremendous potential of online chats to enhance learners' interest in cultural exchange and the use of language for personal reasons going beyond the requirements of their courses.

\section{Acknowledgments}

We would like to thank Shino Mueller and Yun-Wei Wang for all of their help in creating the Japanese and Chinese survey materials and the Japanese abstract.

Charles M. Mueller teaches Cognitive Linguistics and Second Language Acquisition at Fuji Women's University in Sapporo. His recent research has focused on metaphor within religious discourse.

Allen Walzem teaches English at Southern Taiwan University of Science and Technology. His research has focused on English and American literature and film studies.

\section{References}

Akiyama, Y. (2014). Using Skype to focus on form in Japanese telecollaboration: Lexical categories as a new task variable. In S. Li \& P. B. Swanson (Eds.), Engaging language learners through technology integration: Theory, applications, and outcomes (pp. 181-209). IGI Global. https://doi.org/10.4018/978-1-46666174-5.ch009 
Belz, J. A. (2003). Linguistic perspectives on the development of intercultural competence in Telecollaboration. Language Learning \& Technology, 7(2), 68-117. https://doi.org/10125/25201

Bueno-Alastuey, M. C. (2011). Perceived benefits and drawbacks of synchronous voice-based computer-mediated communication in the foreign language classroom. System, 24(5), 419-432. https://doi.org/10.1080/09588221.2011.574639

Bueno-Alastuey, M. C. (2013). Interactional feedback in synchronous voice-based computer mediated communication: Effect of dyad. System, 41(3), 543-559. https://doi.org/10.1016/j.system.2013.05.005

Byram, M. (1997). Teaching and assessing intercultural communicative competence. Multilingual Matters.

Cao, Y., \& Philp, J. (2006). Interactional context and willingness to communicate: A comparison of behavior in whole class, group and dyadic interaction. System, 34(4), 480-493. https://doi.org/10.1016/j.system.2006.05.002

Clément, R., \& Kruidenier, B. G. (1983). Orientations in second language acquisition: 1 . The effects of ethnicity, milieu, and target language on their emergence. Language Learning, 33(3), 273-291. https://doi.org/10.1111/j.1467-1770.1983. tb00542.x

Cziko, G. A. (2004). Electronic tandem language learning (eTandem): A third approach to second language learning for the 21st century. CALICO Journal, 22(1), 25-39. https://doi.org/10.1558/cj.v22i1.25-39

Develotte, C., Guichon, N., \& Vincent, C. (2010). The use of the webcam for teaching language in a desktop videoconferencing environment. ReCALL, 22(3), 293-312. https://doi.org/10.1017/S0958344010000170

Dooly, M. (2017). Telecollaboration. In C. A. Chapelle \& S. Sauro (Eds.), The handbook of technology and second language teaching and learning (pp. 169-183). Wiley Blackwell. https://doi.org/10.1002/9781118914069.ch12

Freiermuth, M., \& Huang, H.-c. (2012). Bringing Japan and Taiwan closer electronically: A look at an intercultural online synchronic chat task and its effect on motivation. Language Teaching Research, 16(1), 61-88. https://doi. org $/ 10.1177 / 1362168811423341$

Freiermuth, M., \& Huang. H.-c. (2018). Assessing willingness to communicate for academically, culturally, and linguistically different language learners: Can English become a virtual lingua franca via electronic text-based chat? In B. Zou \& M. Thomas (Eds.), Handbook of research on integrating technology into contemporary language learning and teaching (pp. 57-85). IGI Publishing. https://doi.org/10.4018/978-1-5225-5140-9.ch004

Freiermuth, M., \& Jarrell, D. (2006). Willingness to communicate: Can online chat help? International Journal of Applied Linguistics, 16(2), 189-212. https://doi. org/10.1111/j.1473-4192.2006.00113.x 
Gardner, R. C., Moorcroft, R., \& Metford, J. (1989). Second language learning in an immersion programme: Factors influencing acquisition and retention. Journal of Language and Social Psychology, 8(5), 287-305. https://doi. org/10.1177/0261927X8985002

Hancock, M. (1997). Behind classroom code switching: Layering and language choice in L2 learner interaction. TESOL Quarterly, 31(2), 217-235. https://doi. org/10.2307/3588045

Helm, F. (2015). The practices and challenges of telecollaboration in higher education in Europe. Language Learning \& Technology, 19(2), 197-217. https://doi. org/10125/44424

Kurek, M., \& Müller-Hartmann, A. (2017). Task design for telecollaborative exchanges: In search of new criteria. System, 64(1), 7-20. https://doi.org/10.1016/j. system.2016.12.004

Li, S. (2010). The effectiveness of corrective feedback in SLA: A meta-analysis. Language Learning, 60(2), 309-365. https://doi.org/10.1111/j.14679922.2010.00561.x

MacIntyre, P. D. (1994). Variables underlying willingness to communicate: A causal analysis. Communication Research Reports, 11, 135-142. https://doi. org/10.1080/08824099409359951

MacIntyre, P. D. (2007). Willingness to communicate in the second language: Understanding the decision to speak as a volitional process. Modern Language Journal, 91(4), 564-576. https://doi.org/10.1111/j.1540-4781.2007.00623.x

MacIntyre, P. D., Babin, P. A., \& Clément, R. (1999). Willingness to communicate: Antecedents and consequences. The Communication Quarterly, 47(2), 215-229. https://doi.org/10.1080/01463379909370135

MacIntyre, P. D., Baker, S. C., Clément, R., \& Conrad, S. (2001). Willingness to communicate, social support, and language-learning orientations of immersion students. Studies in Second Language Acquisition, 23(3), 369-388. https://doi. org/10.1017/S0272263101003035

MacIntyre, P. D., Baker, S. C., Clément, R., \& Donovan, L. A. (2003). Talking in order to learn: Willingness to communicate and intensive language programs. The Canadian Modern Language Review, 59(4), 589-607. https://doi.org/10.3138/ cmlr.59.4.589

MacIntyre, P. D., \& Charos, C. (1996). Personality, attitudes, and affect as predictors of second language communication. Journal of Language and Social Psychology, 15(1), 3-26. https://doi.org/10.1177/0261927X960151001

MacIntyre, P. D., Clément, R., Dörnyei, Z., \& Noels, K. A. (1998). Conceptualizing willingness to communicate in a L2: A situational model of L2 confidence and affiliation. The Modern Language Journal, 82(4), 545-562. https://doi. org/10.1111/j.1540-4781.1998.tb05543.x 
MacIntyre, P. D., \& Legatto, J. J. (2011). A dynamic system approach to willingness to communicate: Developing an idiodynamic method to capture rapidly changing affect. Applied Linguistics, 32(2), 149-171. https://doi.org/10.1093/applin/ amq037

MacIntyre, P. D., Noels, K. A., \& Clément, R. (1997). Biases in self-ratings of second language proficiency: The role of language anxiety. Language Learning, 47(2), 265-287. https://doi.org/10.1111/0023-8333.81997008

Mackey, A. (2006). Feedback, noticing and instructed second language learning. Applied Linguistics, 27(3), 405-430. https://doi.org/10.1093/applin/ami051

Mackey, A., \& Goo, J. (2007). Interaction research in SLA: A meta-analysis and research synthesis. In A. Mackey (Ed.), Conversational interaction in second language acquisition: A collection of empirical studies (pp. 407-452). Oxford University Press.

Meguro, A., \& Bryant, T. (2010). Finding language partners in unexpected places: Skype and social networking for USA-Japan telecollaboration. In S. Guth \& F. Helm (Eds.), Telecollaboration 2.0: Language, literacies and intercultural learning in the 21st century (pp. 453-463). Peter Lang.

Meunier, L. E. (1998). Personality and motivational factors in computer-mediated foreign language communication. In J. A. Muyskens (Ed.), New ways of learning and teaching (pp. 145-197). Heinle and Heinle.

O’Dowd, R., \& Waire, P. (2009). Critical issues in telecollaborative task design. Computer Assisted Language Learning, 22(2), 173-188. https://doi. org/10.1080/09588220902778369

Saito, K., \& Akiyama, Y. (2017). Video-based interaction, negotiation for comprehensibility, and second language speech learning: A longitudinal study. Language Learning, 67(1), 43-74. https://doi.org/10.1111/lang.12184

Tian, J., \& Wang, Y. (2010). Taking language learning outside the classroom: Learners' perspectives of eTandem learning via Skype. Innovation in Language Learning and Teaching, 4(3), 181-197. https://doi.org/10.1080/17501229.201 0.513443

Warschauer, M. (1996). Comparing face-to-face and electronic discussion in the second language classroom. CALICO Journal, 13(2/3), 7-26.

Yashima, T. (2002). Willingness to communicate in a second language: The Japanese EFL context. The Modern Language Journal, 86(1), 54-66. https://doi. org/10.1111/1540-4781.00136

Ziegler, N. (2016). Synchronous computer-mediated communication and interaction: A meta-analysis. Studies in Second Language Acquisition, 38(3), 553-586. https://doi.org/10.1017/S027226311500025X 